\title{
Reduction of Harmful Emissions from Domestic Power Generator Usage in Nigeria - A Tribological Approach
}

\author{
Animashaun Lukman Aremu
}

\author{
Research Scholar \\ Department of Mechanical Engineering \\ Lagos State Polytechnic \\ Ikorodu, Lagos State
}

Nigeria

\begin{abstract}
Worldwide concern for the release of harmful emission from Internal Combustion (IC) engines requires the optimization of the quantity of fuel used, types of fuel blend used and type of lubrication utilized. In Nigeria, the electrical power requirements of many households rely more on alternative sources such as Solar systems and fossil fuel-powered generators. The use of these generators is known to produce exhaust fumes that are harmful to humans and the environment. This research studied the effect of using two different commercially available lubricating oils for gasoline-fueled power generators for domestic applications in comparison to used oils with the aim to understanding the behavior of Boron additive with SAE 40, SAE 20W50, and aged oils. In addition, a comparison of torque and emission measurements from oils containing boron to oils without the Boron additives at different speeds was done. Measurements of speed, torque and emission were respectively carried out using a digital tachometer, torque meter (contact type), and 5-gas exhaust analyzer. Results from this study indicated a general decrease in torque with increased speed for all the lubricating oils. This is in agreement with the results of similar studies on torque outputs from IC engines with increasing speeds. However, oils lubricated with Boron additives minimized this loss at a different speed more in SAE 20W50, SAE 40 than in used oils. Carbon monoxide emission from these results indicated that generators lubricated by aged oils are highest at all speed ranges irrespective of Boron additive inclusion. Cleanliness from a gasoline-powered generator is possible if Boron additive is added to lubricating oils. The concentration of $\mathrm{NO}_{x}$ emission was found to rise considerably only when operated at the highest speed for aged oils. The results of this study indicated that tribofilms formed by boron-containing oils played a role in preventing torque reduction or power loss and $\mathrm{CO}$ emissions from power generators for domestic use. This behavior was attributed to the friction-reducing boric acid and wear resistance borate glass contained within the trilayer. However, tribofilms formed by used oils on tribological parts of the engine gave poor torque reduction results in comparison to that provided by fresh oils. This indicated that when lubricating oils in power generators used in homes are aged beyond the recommended interval for replacement, substantial power loss and harmful emissions are released to the surroundings.
\end{abstract}

Key Words: Boron, Tribofilms, Torque, Emission, Generators.

\section{INTRODUCTION}

Emissions from burning fossil fuel in IC engines are a mixture of harmful and heat-trapping gases such as $\mathrm{CO}_{2} \mathrm{CO}_{2}, \mathrm{NO}_{\mathrm{x}}, \mathrm{SO}_{\mathrm{x}}$, particulate matter, and un-burnt hydrocarbons that can be harmful to humans and the environment. The degree of well-being and industrial development of any nation is related to its per capita energy consumption. Based on power generation of about $3000-$ $5000 \mathrm{MW}$ of electricity for a population of about 200 million, Nigeria is known to have average power consumption per capita of 14 watts based on electric power generation output [1]. This implies that the public utility companies for electricity supply have not been able to meet the required demands. Hence, most Nigerians are compelled to invest in electric power generators tp power the industries and homes. Owning a portable gasoline generator in Nigeria today is not only essential but the norm. Given the different challenges faced by electricity consumers in Nigeria, $73 \%$ of the population is known to use fossil-fuel-powered electric generators [2]. These generators work on either 2-stroke or 4-stroke cycle principles. 
In a building of twenty rooms, not less than 15 electric generators would be working simultaneously; emitting thick clouds of environmentally unfriendly gases for very long hours [3], as shown in Error! Reference source not found..The most toxic of these product gases is carbon monoxide which is virtually invisible. It is an odorless and colorless effluent which if inhaled continuously, can becomes fatal. The exhaust produced by a typical $5 \mathrm{~kW}$ generator contains as much carbon monoxide as that of about half a dozen idling cars. A portable electric power generator (PPG) is a gasoline or diesel-powered device which provides temporary electrical power up to certain wattage and is designed for outdoor use. Users often place generators near or in their homes due to generator theft and noise to neighbors. There is one that is particularly nicknamed 'I pass my neighbor' in Nigeria. This is about 900 Watt power output and needs its lubricating oil mixed with petrol. Hence, the lubricating oils for this type of generator will burn with its fuel. This could likely produce more $\mathrm{CO}$ and $\mathrm{CO}_{2}$ in the exhaust stream than power generators whose fuel and lubricants are not mixed. However, the low unit cost of this brand makes it affordable for small household needs.

A study of the emission values of passenger vehicle in idle mode in comparison to regulated values showed that age and fatigue will produce some poor performances of engine and high emission values in the aged vehicle [4]. Another study evaluated the impact of emissions from generating sets on air quality and human health in selected areas of Abeokuta city, Nigeria showed that the level of pollutants was highest near generator operating sites [5]. A study had measured and modeled the effects of portable gasoline-powered generator exhaust on indoor Carbon Monoxide level with modified, prototype generators (i.e., with CO emission controls) showed CO emissions reductions of over $90 \%$ depending on the specific emission controls and operating conditions and no trend toward higher emission rates when $\mathrm{O}_{2}$ levels dropped to $18 \%$ [6].

The objective of this research is to study the effect of using two different commercially available lubricating oils for gasolinefueled power generators for domestic applications in comparison to used oils. This research conducted aims to study the behavior of Boron additive with SAE 40, SAE 20W50, and aged oils. A comparison of results of torque and emission measurements from oils containing boron to oils without the Boron additives at different speeds is expected to provide information on the role of borate tribofilms formed by boron-containing oils in preventing torque reduction or power loss and $\mathrm{CO}$ emissions from power generators for domestic use.

\section{LITERATURE SURVEY}

The conventional additives used in lubricating oils have been used in IC engines for more than 60 years and have zinc, phosphorus, and sulphur compounds in the by-product of their combustion that impedes the performance of emission control system of internal combustion engines and exhaust particulate matter [3]. At high concentrations in the lubricating oils, these are known to form compounds that deactivate the catalytic converters and block particulate filters in vehicles [5]. These are called Sulphated Ash and Phosphorus additives (SAP). However, restrictions due to environmental concerns have over the year been limiting the quantities added to lubricating oil through various legislations from many countries. This reduction could adversely affect the tribological and durability performance of contacting surfaces of the IC engine which can lead to an increase in friction loss, wear of parts, and reduced power output. Hence, the need to investigate alternative Zero-SAP additives in lubricating oils could significantly reduce particulate matter and other harmful emissions from exhaust gases from IC engines used on power generators without impacting adversely on their power outputs and durability.

One type of conventional oils used to lubricate internal combustion engines for gasoline-powered generators is the mono-grade lubricating engine oil classification of SAE 40 that has a viscosity within the defined limits when tested at $100{ }^{\circ} \mathrm{C}$ and $150{ }^{\circ} \mathrm{C}$. It is a high-temperature performance oil and cannot incorporate any polymeric viscosity index improvers. Another type of oil used in gasoline generators is a multi-grade SAE 20W50, designed not to exceed maximum specified viscosity limits at very low temperatures and higher viscosity at $100{ }^{\circ} \mathrm{C}$ than SAE 40 .

Research has shown that oils containing boron additives can significantly reduce $\mathrm{CO}_{2}$ emissions in I.C. engines. Studies on passenger cars using boron-containing lubricating oils shows that lower tailpipe emissions can be achieved on vehicles than oils with conventional additives $[9,10]$. The use of Synthetic borate additives in lubricating oils of internal combustion engines is known to provide antiwear and friction-reducing functions. These can either be organic borate compounds or inorganic borate nanoparticle dispersions to solve the hydrolytic stability problem arising electron-deficient boron with its empty $2 p$ orbitals being easily attacked by multi-electron atoms [7,8]. The friction reducing mechanism of borate reacted layer due to friction and wear (tribofilms) was attributed to both boric acid's $\left(\mathrm{H}_{3} \mathrm{BO}_{3}\right)$ weak van der Waal's forces [9] and vapor adsorption required to unlock its high energy edge of boric acid's site for easy shear [10].

It is therefore imperative to investigate the effects of Zero-SAP additives in oils on emission reduction from these generators without compromising losses in mechanical power output. Besides, there is frequent clogging of the exhaust control system of these generators. This was attributed to particulate matter from the exhaust emission which ultimately leads to frequent maintenance issues [5] and poor durability of the engines [8, 9]. 


\section{PROBLEM DEFINITION OR EXPERIMENTAL WORK}

The effects of exposure to high concentrations of $\mathrm{CO}$ had resulted in some deaths in Nigeria where more than 60 people suffocated to death in 2008 alone. Hence, the use of electric generators by many Nigerians continues to release a monumental amount of GHG to the environment. There has been great economic losses associated with self-generation of electricity using petrol, diesel, and natural gas generators was found to be very high [4, 11]. The United States' Consumer Product Safety Commission reported that five out of 104 deaths caused by generator carbon monoxide (CO) poisoning were associated with a generator that was placed outside the home near open windows, doors, or vents [12]. A study on the environmental impact of a portable power generator on indoor air quality determined the emission factors of $\mathrm{CO}$ from gasoline-powered portable power generators (PPG) [13]. The study revealed that source CO concentration from PPG was found to be very high at $24.289 \mathrm{x} 10^{3}$ $\mathrm{mg} / \mathrm{m}^{3}$. The CO emission factors were obtained as $2.2366 \times 10^{3} \mathrm{~kg} / \mathrm{m}^{3}$ of fuel consumed and $9.5411 \times 10^{6} \mathrm{~kg} / \mathrm{hr}$. of activity.

Due to poverty level, unauthorized engine oil usage in PPG could lead to power loss and emissions in Nigeria. Sometimes, engine oils are obtained from unknown sources due to their low costs. Emissions from different types of generators are shown in Figure 3- 1.

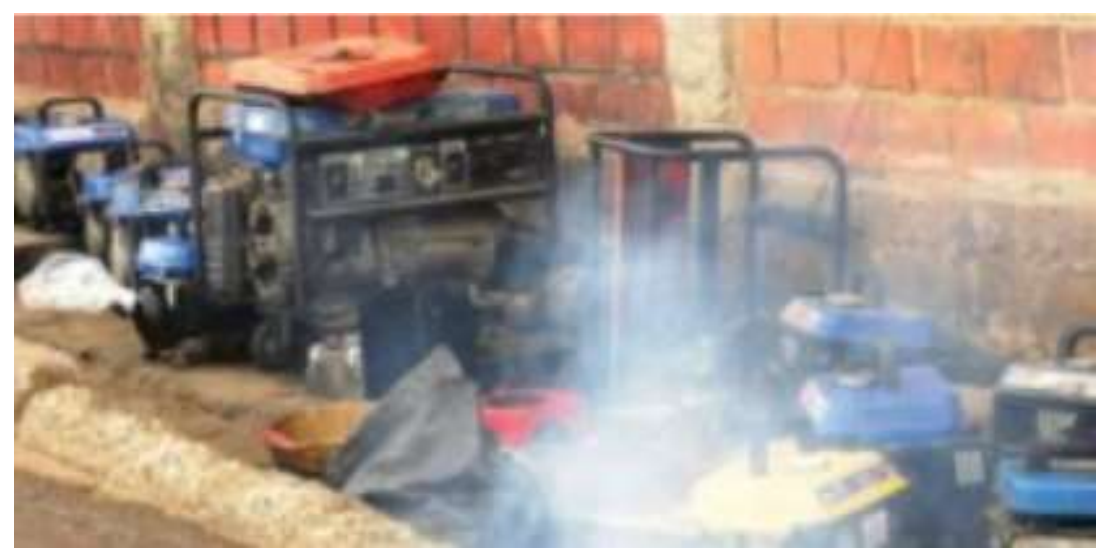

Figure 3- 1 Exhaust emissions from industrial generators [14]

With an increasing population of about 3.3\% per arum, emissions from generator usage could rise exponentially if concrete steps are not taken to reduce the effects of the fuel and oil sources. The fuel sources can be controlled from the refining processes and the type of crude used. However, the type of base oil and additives used defines the lubricating oil performance, emissions, and durability of the parts of the IC engines used in these power generators.

In modern vehicles, powered by IC engines, the effect noxious gases are controlled by the use of exhaust catalytic converters and particulate filters installed in them. However, generators for domestic applications do not have these devices. These emissions can arise from the type of fuels, base oil, and chemical agents (additives) used in powering and lubricating oil the internal combustion engines (IC) in these generators. Hence, the need to investigate the effects of different engine oils and changes in additives used in lubricating oils on power outputs and emissions from portable generator usage in Nigeria is necessary.

This study used a new EC5800CX four-stroke internal combustion engine portable gasoline power generator of $2.5 \mathrm{~kW}$ and $230 \mathrm{~V}$ rated power output and voltage respectively for various tests as shown in Figure 3- 2 (a). The alternator of the generator was dis-coupled from the main engine to access the actual mechanical power output from the crankshaft using a TQ-8800 hand-held torque meter from Lutron Inc. as shown in Figure 3- 2 (b). The digital torque meter is expected to measure the friction torque. This is subtracted from the theoretical torque the generator can transmit to obtain the actual torque output at different speeds for every oil change.

The lubricants used for lubrication in these tests are of three main types and their mixtures with boron-containing friction modifier. These are SAE 40, SAE 20W50, Used oil, boron-containing SAE 40 oils, boron-containing SAE 20 W50 oils, and boron-containing used Oils. The oils were obtained from authorizing petrol or gas station and the friction modifier contains potassium borate nana-particles. Research has shown that oils containing boron additives can significantly reduce CO emissions in I.C. engines. Studies on the IC engine of passenger cars ran with boron-containing lubricating oils showed that lower tailpipe emissions are possible on vehicles than oils with conventional additives

$[15,16]$. This study will use a synthetic hydrated potassium borate nano-particle dispersion with nanoparticle size of about 50-100 $\mu \mathrm{m}$ in an organic matrix [17]. It has a product name of AR9100 oil additive and supplied by ARCHOIL Inc. The addition of 
synthetic hydrated potassium borate was $2.5 \mathrm{wt} \%$ in each of the oils. Also, the ensured the same type of used oils was utilized for all the tests and that the sample used was collected from a source where the mileage for oil change had exceeded the recommended limits. In this way, it is assumed that all the active fiction reduction and antiwear chemical agents have significantly diminished.

Emissions from each of these tests are continuously obtained using a TotalGas 8050, 5-gas $\left(\mathrm{CO}, \mathrm{CO}_{2}, \mathrm{HC}, \mathrm{O}_{2}\right.$, and NO) exhaust analyser from Motor SCAN as shown in Figure 3- 2 (c) and (d). The speed of the engine was varied by adjusting the throttle valve of the speed governor. For every speed changes, a DT-2235B digital contact/surface tachometer is used. The results of torque output concerning emissions from these generators will be determined from a hand-held digital torque meter and tachometer. These are expected to provide information and evidence on whether emission reduction occurs due to boron-containing oil usage without adversely affecting durability and power output.

Data collected on emissions from the gasoline power generators will determine whether lubricating oils containing boron have significant effects on emission from power generators compared to oils containing no boron at different speeds. Also, durability measurements will be determined by comparing the performance of the oils with that of used oil in terms of mechanical power and emission at different speeds.

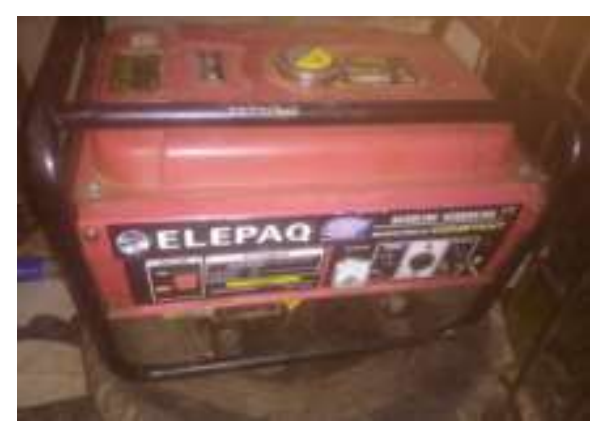

(a)

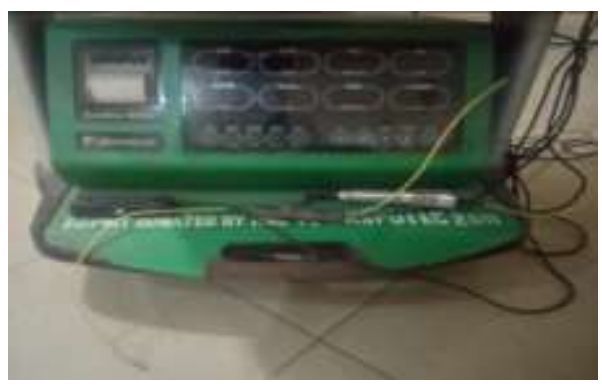

(c)

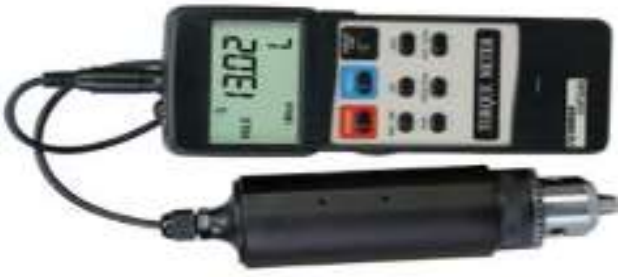

(b)

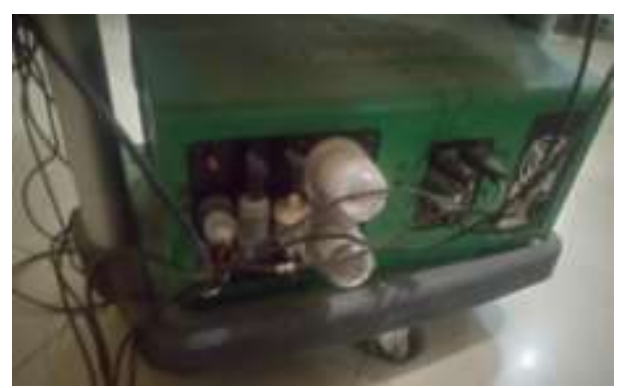

(d)

Figure 3- 2 (a) 2.5kVA Generator, (b) Hand-held torque meter, (c) Front end of 5-Gas exhaust analyzer, and

(d) Rear end of 5-Gas exhaust analyzer

\section{RESULTS AND DISCUSSION}

\subsection{Variation of Torque with Speed}

Results from this study using two conventional oils in comparison to used oil and when boron-containing friction modifier additives are added to the three oils are shown in Figure 4- 1. The results are expected to provide information on emissions from electric power generators for domestic use at different speeds. 


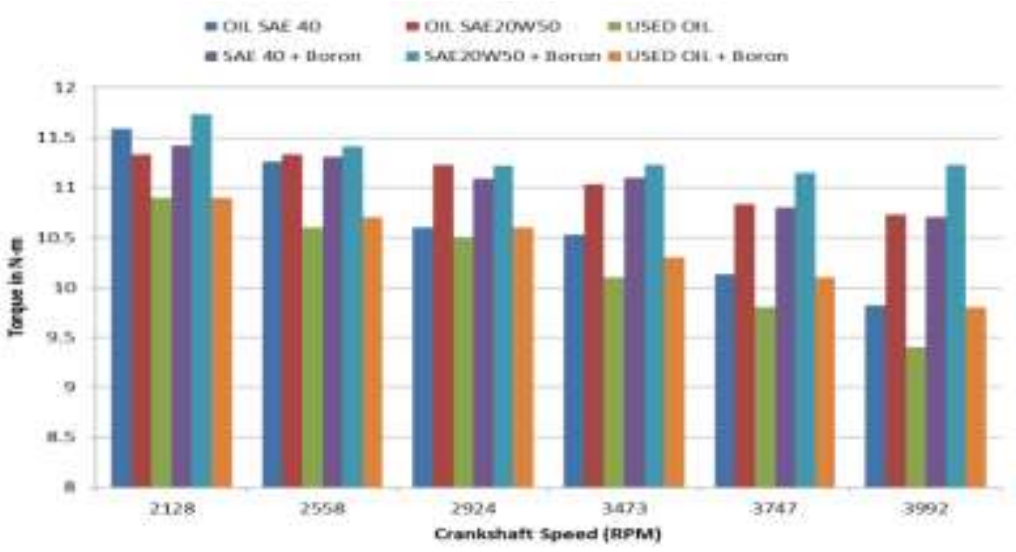

Figure 4- 1 Changes in torque with respect to speed for various oil combinations

The results indicated in Figure 4- 1 shows there was a significant decrease in torque for all the oils used in these tests with and without boron for the speed range used in these tests. This is consistent with results from similar studied [16, 18]. Torque reduction with increasing speed was highest on used oils irrespective of the presence of boron additives. This is indicative of the poor tribological performance of used oil in running a power generator when compared to the performances of SAE 40 and SAE 20W50 oils. However, the effect of boron additives on the tribological performances of all the oils shows a significant torque increase at a higher speed than at lower speeds. This indicated that boron-containing additives gave considerable benefits in torque transmission at these high speeds for all the test oils. Hence, these tests can confirm that power transmission by the generator is higher at lower speeds than at higher speeds. Besides, used oils gave the poorest tribological performance irrespective of performance enhancement additives.

\subsection{VARIATION OF CARBON MONOXIDE EMISSION WITH SPEED}

The variations in the level of one of the constituents of the exhaust gas are the harmful Carbon Monoxide emission with engine speed is shown in Figure 3-2.

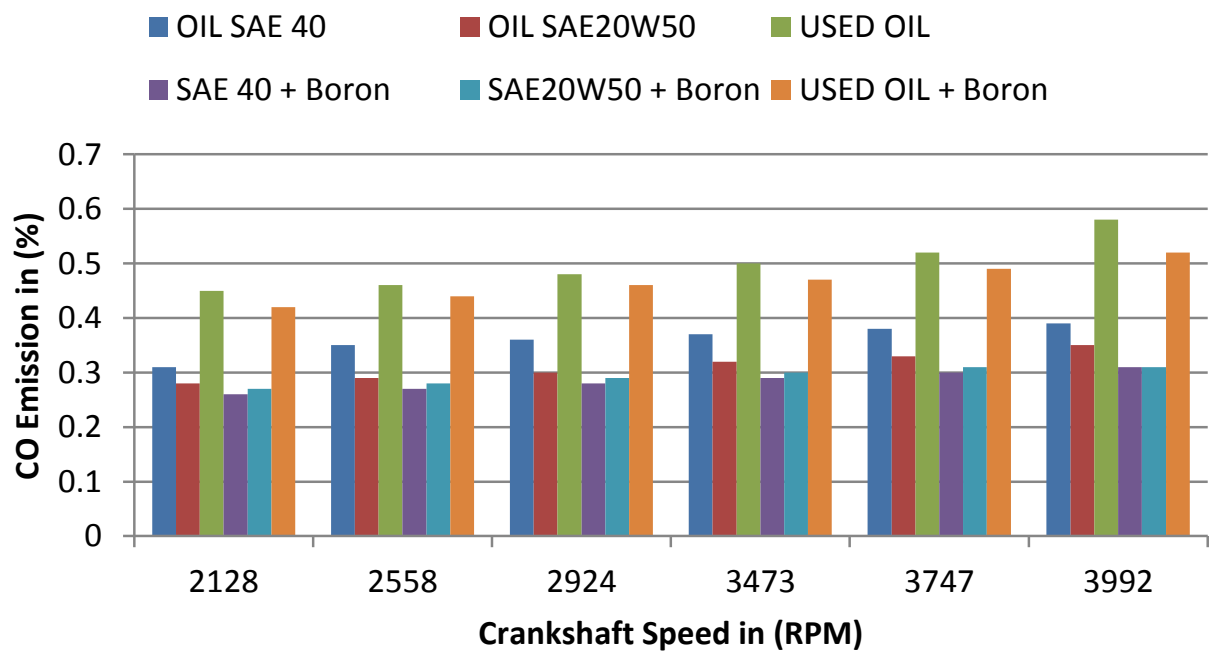

Figure 4- 2 Changes in Carbon monoxide emission with speed for different oils

The results shown in Figure 4- 2 indicated that Carbon Monoxide in the emission stream increased within the speed range of the tests for engine oil-types: SAE 40 (26\%), SAE 20W50 (20\%), and Used Oil (29\%). This shows that lower CO emission occurred with SAE 20W50 than SAE 40. On the other hand, used oil has the highest CO in the emission stream. This is an indication that used oil applications in lubricating internal combustion engines produce harmful $\mathrm{CO}$ emissions to the surroundings. Increase in Carbon II oxide emission stream in the emission stream with boron additives in all the oil samples used to run the generator within the speed range of these tests gave: SAE $40+$ Boron (19\%), SAE 20W50 + Boron (15\%) and (24\%) for used oil + Boron). This indicated that significant CO reduction occurred with SAE $40+$ B and SAE 20W50 + Boron, but not with used oil + Boron; if 5\% significant figure is used as the threshold. Hence the addition of boron additives cannot reduce $\mathrm{CO}$ emission from used oil. This is unlike the response of fresh oils to $\mathrm{CO}$ emission when they are blended with boron additives. 


\subsection{VARIATION OF UNBURNT HYDROCARBON WITH ENGINE SPEED}

A measure of engine cleanliness concerning engine speed can be obtained from the amount of un-burnt hydrocarbon measured during the test as shown in Figure 4- 3.

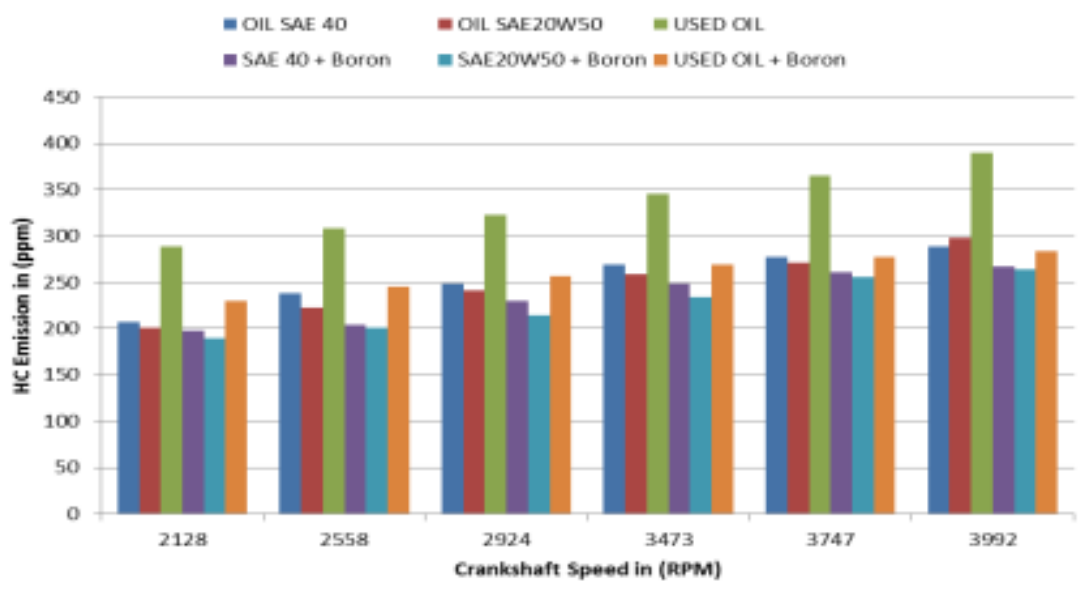

Figure 4- 3 Changes in Un-burnt hydrocarbon with various oil combinations

The results indicated that used oils gave higher amount of un-burnt hydrocarbon than SAE 40 and SAE 20 W50 oils with increasing speed. This is an indication that utilization of used oil for lubrication in electric power generator will produce more UHC fuel than fresh fully formulated oils. Hence, the cleanliness of portable electric power generators IC engines lubricated by used oil is poorer than SAE 40 and SAE 20W50. On the other hand, boron additives inclusion in the fresh oils gave reduced unburnt-hydrocarbon emission as from $2559 \mathrm{rpm}$ speed which continued to decrease up to $3992 \mathrm{rpm}$. However, this reduction was highest when a boron additive was added to aged oil at all speed range of the tests. However, the differences become considerable as the speed increases when compared to the lowest speed. This result is consistence with that obtained in the literature [12].

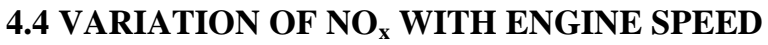

Another harmful gas that was investigated is the amount of $\mathrm{NO}_{\mathrm{x}}$ in the emission stream as shown in Figure 4- 4.

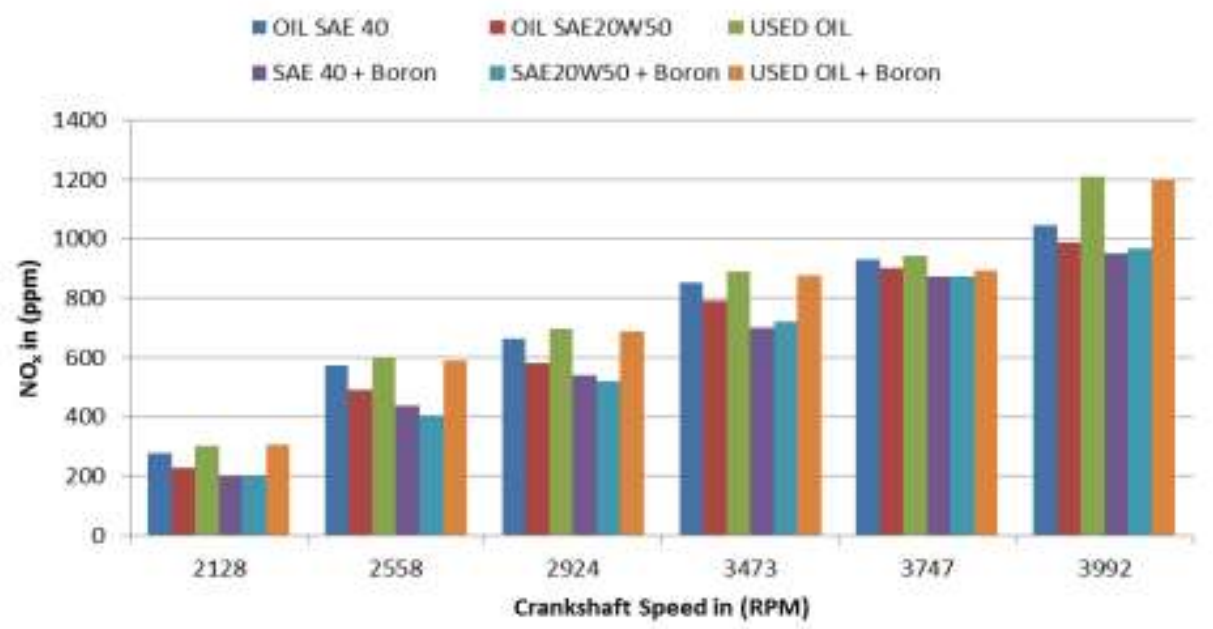

Figure 4- 4 A measurement of variation in $\mathrm{NO}_{\mathrm{x}}$ with different oils and speed

The results shown in Figure 4- 4 indicated that $\mathrm{NO}_{\mathrm{x}}$ emission is lowest at the minimum speed of the tests for all the oils compared to other speeds. Other key findings of this result the insignificant changes in $\mathrm{NO}_{\mathrm{x}}$ emission for used oil with and without Boron at all speed during the tests. This is unlike results obtained for SAE 40 and SAE 20W50 with and without Boron that gave significant changes at other speeds apart from the lowest speed of the tests. This is an indication that the boron additive has a significant influence in this process of $\mathrm{NO}_{\mathrm{x}}$ reduction.

\subsection{DISCUSSION}

The results of this study were able to compare output torques from gasoline-powered generators that were lubricated by fresh SAE 40 and SAE 20W50 oils which showed that fresh multi-grade oil had less torque reduction than fresh mono-grade oil at different 
operational speeds of the tests. This may be attributed to the blending of a low-viscosity oil with special additives called Viscosity Index Improver (VII) VII to form multi-grade oils. Hence, the ability of SAE 20W50 to combine good starting and friction properties of a thin oil at low temperatures with the good lubricating properties of a more viscous oil at high temperatures could have made this possible. Besides, the friction-reducing properties of boron additives further enhanced its performance at higher speeds. On the other hand, reduction in torque was highest with used oils with and without the boron additives. This may be attributed to the composition of used oil which may contain water, salt, broken down additive components, varnish, gum, and other materials [19]. Thermal degradation of the used oil could also have affected the poor performances with increasing speed compared to fresh oils.

Emissions in form of $\mathrm{CO}, \mathrm{UHC}$, and $\mathrm{NO}_{\mathrm{x}}$ in the exhaust stream were better controlled by fresh SAE $20 \mathrm{~W} 50$ oil than fresh SAE 40 and used oil. The addition of boron additive further enhanced this performance. These results indicated that once lubricating oils in power generators start to age, oxidation of the oil with time could produce impurities like unsaturated, aldehydes, asphalt-like sludge, phenolic compounds, alcohols, acidic compounds, non-stable products of hydrocarbons [20] which adversely affects its tribological performance. Besides, the $\mathrm{NO}_{\mathrm{x}}$ emission effect is not significant by boron additive in used oil. This behavior is due to the used of oil-absorbing nitrogen oxides and the acidic fuel of combustion exhaust gas.

Because of the results from this study, it is pertinent to emphasize the harmful effect of $\mathrm{CO}$ emission that could result when aged oil is used to run power generators apart from the power loss that is associated with its electricity use. The dominant oxidation reaction for carbon monoxide in an engine is given by Equation 1 [21].

$$
\mathrm{CO}+\mathrm{OH} \leftrightarrow \mathrm{CO}_{2}+\mathrm{H} .
$$

The oxidation of $\mathrm{CO}$ depends on the availability of the $\mathrm{OH}$ radicals and competes with the hydrocarbon concentration. As $\mathrm{CO}$ oxidation has relatively higher activation energy, its oxidation is delayed until the original hydrocarbon and the intermediate hydrocarbon species have been consumed. $\mathrm{OH}$, concentration then rises to higher levels, which that thereby convert the $\mathrm{CO}$ to $\mathrm{CO}_{2}[22]$.

The un-burnt hydrocarbon for age oil with and without boron was found to increase significantly with speed by about $23 \%$ and $40 \%$ respectively. This indicated that the fuel economy potentials of generator lubricated by aged oils are poor. Also, some of this un-burnt hydrocarbon may find their way into the exhaust system that could result in the frequent clogging of the exhaust muffler. Besides, engine oil dilution of the lubricating oil by the un-burnt hydrocarbon can occur. This could result in loss of power, frequent maintenance of the generators, and increased downtime. However, results from this study had excluded the possibility of evaporative emission of hydrocarbon fuel. In practice, this cannot be neglected. Hence, the possibility of values obtained from this study to have higher values than recorded.

The behavior of oxides of Nitrogen from emissions at different oils and speeds shows that the highest $\mathrm{NO}_{\mathrm{x}}$ emissions are obtained at the highest speed for all oil combinations. This is an indication that running the power generator at a very high speed may result in more $\mathrm{NO}_{\mathrm{x}}$ emissions into the atmosphere. Hence, it is advisable to run the engine at the recommended speed range by the manufacturer in other to minimize $\mathrm{NO}_{\mathrm{x}}$ emission. Also, aged oils gave about $21 \%$ higher $\mathrm{NO}_{\mathrm{x}}$ emission compared to other oils used in these tests. This is an indication that the Boron additive played little role in minimizing $\mathrm{NO}_{\mathrm{x}}$ emission.

The behavior of boron-based tribofilms on torque outputs in this study was able to provide torque reduction. This may be related to its friction and antiwear mechanisms. The friction reducing mechanism was due to the interaction of moisture in the air and which passivated the edge sites of lamellar structured boric acid. On the other hand, the antiwear performance was due to the digestion of abrasive iron oxide by boron oxide to form wear resistance borate glass [23, 24]. Carbon monoxide emission reduction results from this study were in agreement with a research study on internal combustion engines on cars [16].

\section{CONCLUSIONS}

The followings are the conclusions of experimental results of measurements of torque outputs and emissions from gasolinepowered domestic generator lubricated by SAE 40, SAE 20W50, Aged oil (Used oil), SAE40 + Boron additives, SAE20W50 + Boron additives, and used oil + Boron based additives. There was a general decrease in torque with increased speed for all the lubricating oils. This indicated that substantial power loss can result from running generators at a higher speed than recommended by the manufacturer which can affect the performance of power generators despite the use of Boron additive. Considerable power loss occurred more in used oils than fresh oils for all test conditions. This indicated that when lubricating oils in generators is aged or old, considerable power loss can reduce its efficiency. Carbon monoxide emission from generators lubricated by aged oils is highest at all speed ranges irrespective of Boron additive inclusion or not. This indicates that hazards from Carbon monoxide poisoning are highest when oils are aged in generators used for power generation in homes. Un-burnt hydrocarbon emission is highest in aged oils without Boron additive at all speed but was reduced when Boron additive was included. This indicated the better engine cleanliness of generators lubricated by used oil can be achieved if Boron additive is added to the oil. The emission of $\mathrm{NO}_{\mathrm{x}}$ was considerable when the generator was running at the highest speed in these tests for aged oils irrespective of whether 
Boron additives were added or not. This is an indication that aged oils in generators do not constitute a serious health hazard until the generator is run at speeds far higher than what the manufacturers recommended. The results of this study indicated that the Boron additive played a role in preventing torque reduction or power loss and emissions from power generators used in homes. Also, results from this project indicated the unsuitability of aged oils in generators in terms of torque outputs and harmful emission released to the atmosphere. This study has shown that boron additives utilization in carbon monoxide emission reduction in vehicles is also possible in gasoline-powered generators used for domestic applications. Future work should consider the measurement of brake thermal efficiency and specific fuel consumption for different oils and speeds.

\section{ACKNOWLEDGMENTS}

This research was funded by the Tertiary Education Trust Fund (TETFUND) and the Nigerian Government. The author wishes to thank TETFUND, Federal Government of Nigeria, and management of Lagos State Polytechnic for their supports in sponsoring this research.

\section{REFERENCES}

1. Akande, T.M., \& Owoyemi, J., Awareness and Attitude to Social and Health Hazards from Generator Use in Ayigba, Nigeria. Medwell Journal. Research Journal of Medical Sciences, (2008). 2(4): p. 185-189.

2. Akin, A.O., False Adaptive Resilience: The Environmental Brutality of Electric Power Generator Use in Ogbomoso, Nigeria. World Environment, 2016. 6(3): p. 71-78.

3. Adebayo, W., Temperature trends and variability in Nigeria., 1991, University of Ibadan, Nigeria.

4. Aduagba, O., J. Amine, and M. Oseni, Investigating Emission Values of a Passenger Vehicle in the Idle Mode and Comparison with Regulated Values. Editorial Board: p. 13.

5. Oguntoke, O. and A. Adeyemi, Degradation of urban environment and human health by emissions from fossil-fuel combusting electricity generators in Abeokuta metropolis, Nigeria. Indoor and Built Environment, 2017. 26(4): p. 538550 .

6. Emmerich, S.J., A.K. Persily, and L. Wang, Modeling and measuring the effects of portable gasoline powered generator exhaust on indoor carbon monoxide level2013: US Department of Commerce, National Institute of Standards and Technology.

7. Spikes, H., Low-and zero-sulphated ash, phosphorus and sulphur anti-wear additives for engine oils. Lubrication Science, 2008. 20(2): p. 103-136.

8. Choudhary, R. and P. Pande, Lubrication potential of boron compounds: an overview. Lubrication Science, 2002. 14(2): p. 211-222.

9. $\quad$ Erdemir, A., R.A. Erck, and J. Robles, Relationship of hertzian contact pressure to friction behavior of self-lubricating boric acid films. Surface and Coatings Technology, 1991. 49(1): p. 435-438.

10. Barthel, A.J., J. Luo, and S.H. Kim, Origin of ultra-low friction of boric acid: Role of vapor adsorption. Tribology Letters, 2015. 58(3): p. 1-12.

11. Ugwu, H., et al., Energy and Economic losses due to constant power outages in Nigeria. Nigerian Journal of Technology, 2012. 31(2): p. 181-188.

12. Marcy, N. and D. Ascone, Memorandum: Incidents, deaths, and in-depth investigations associated with carbon monoxide from engine-driven generators and other engine-driven tools, 1990-2004. Bethesda, MD, United States Consumer Product Safety Commission, 2005. 18.

13. Adefeso, I., A study of outdoor-indoor exchange of carbon monoxide from a standby electricity generator. An M. Sc Thesis Submitted to Department of Chemical Engineering, Obafemi Awoolwo University, Ile-Ife, Nigeria. Unpublished, 2010: p. 1-150.

14. Okafor, P., Beware of Generator Fumes they Kill, in NaijaTechGuide, N.T. Lead, Editor 2018: Nigeria.

15. Baş, H. and Y.E. Karabacak, Investigation of the effects of boron additives on the performance of engine oil. Tribology Transactions, 2014. 57(4): p. 740-748.

16. Twigg, M.V., et al., The effect of phosphorus and boron lubricant oil additives on catalyst and engine durability. SAE transactions, 2004. 113(4): p. 948-959.

17. Canter, N., Friction-reducing characteristics T. Tribology \& Lubrication Technology, 2008. 1: p. 1.

18. Patil, K.S.C.A., Performance, Efficiency, and Emissions Characterization of Reciprocating Internal Combustion Engines Fueled with Hydrogen/Natural Gas Blends, 2007: United States.

19. Eman, A. and A.M. Shoaib, Re-refining of used lube oil, II-by solvent/clay and acid/clay-percolation processes. ARPN Journal of Science and Technology, 2012. 2(11): p. 1034-1041.

20. Bridjanian, H. and M. Sattarin, Modern recovery methods in used oil re-refining. Petroleum \& Coal, 2006. 48(1): p. 4043. 
21. Heywood, J.B., Engine types and their operation. Internal combustion engine fundamentals, 1988: p. 1-5.

22. Kuo, K.K., Principles of combustion 2005.

23. Philippon, D., et al., Experimental simulation of tribochemical reactions between borates esters and steel surface. Tribology Letters, 2011. 41(1): p. 73-82.

24. Animashaun, L.A., Tribochemistry of Boron-Containing Lubricant Additives on Ferrous Surfaces for Improved Internal Combustion Engine Performance, 2017, University of Leeds. 